\title{
Study on the development dilemma and breakthrough of the traditional sports of ethnic minority in the northwest of Guangxi under the background of urbanization
}

\author{
Mingrong Yu \\ School of Sichuan Agricultural University, Sichuan 625014, China; \\ 46485549@qq.com
}

Keywords: Urbanization,the northwest of Guangxi,Traditional sports of ethnic minority

\begin{abstract}
The purpose of this paperis to protect the traditional sports of ethnic minorityin the northwest of Guangxi province. By means of field visit, interview and mathematical statistics, the paper investigates to the Miao nationality, theMulaonationality,the Dong nationality and the Maonan nationality in the northwest of Guangxi,and analyses on the current dilemma of the traditional sports of ethnic minority in the northwest of Guangxi.The results show that,in the northwest of Guangxi,the number of population outflow is increasing, traditional production mode is disappearing and traditional sports entertainment projects are squeezing by the modern entertainment projects, which lead to the inheritance of the traditional national sports in the northwest of Guangxi is facing a crisis.So there are suggestions that the local government sports and cultural sector should integrate the traditional nationality sports projects to promote their development and transformation;intensify the efforts to attract the investment and develop local economy,also keep the stability of population structure in minority areas;broaden the channelof the development of national sports in northwest of Guangxi comprehensively.
\end{abstract}

\section{Introduction}

There are twelve minorities in Guangxi province.The Miao nationality,the Dong nationality,theMulao nationality and the Maonan nationality are the main minorities live in the northwest,and except the Miao nationality,all of themare the Guangxi indigenous nationality in the northwest of Guangxi. These four nationalities all have excellent national traditional sports can reflect the characteristics of indigenous culture in Guangxi.There are several typical Guangxi nationalities. The Miao nationality,whichhas a population of 423 thousand,accounts for 5.5 percent of the total population of the Miao nationality.The Miao people are distributed mainly over mountain areas in the north and northwest of Guangxi,and the largest settlements is Miao Autonomous County of Rongshui.The Dong nationalityhas a population of 298 thousand and 700,and most of the people distributed in Sanjiang,Rongshui,Longsheng and LuochengMulao Autonomous County.The population of Mulao nationality is nearly 160 thousand,as much as 98 percent of the total population of the Mulaonationality,distributed mainly over LuochengMulao Autonomous County and neighboring counties. The population of the Maonan nationality is 69 thousand, and most of the Miao people concentrated in Huanjiang, while a few people distribute in Nandan, Hechi, Yishan and Duan.

Ethnic minorities in Guangxi mainly located in county towns and villages where are backward and remote, and there is little influence by modern civilization before the Reform and Opening-up, so the traditional national sports has been got preferable protection and inheritance. With the further promotion of the Reform and Opening-up and the urbanization, their living environment, production methods, entertainment mode and education condition have been greatly improved. For the human progress, this is a result that all of us expect, but as far as the development of local traditional national sports, the fact is the opposite. Because of the social development, traditional production and living mode will change, which may cause the development of traditional sports to a crisis. 


\section{The present dilemma about traditional minority national sports in the northwest of Guangxi}

With the transition from planned economy to market economy, industry is becoming the leading industry gradually, and the manufacturers are turning into the economic organization form. Then because of the crises about both traditional agriculture and family, the local traditional national sports are conditioned indirectly.

2.1 Minority nationality at the area of northwest in Guangxi province whose structure of populations' reforming shocks at national and traditional physical culture.

The development of national and traditional physical culture is influenced by the existent soil. The items of national and traditional physical culture, at the area of northwest in Guangxi province, is combined with the conventional life way. The number of migrant workers is arising with reforming about the populations' structure, resulting the environment of gym is destroyed and is bad for its development.

Table 1 The statistic chart is about the Miao nationality、Dong Minority、Mulao nationality and Mao Nan nationality at the area of northwest in Guangxi province. (Unit:family)

\begin{tabular}{cccll}
\hline \multicolumn{2}{c}{ Month Yao $(\mathrm{n}=60)$} & Dong(n=60) & Mulao(n=60) & Maonan(n=60) \\
\hline 2013 & $17,28.3 \%$ & $15,25 \%$ & $21,35 \%$ & $28,48.3 \%$ \\
2014 & $25,41.7 \%$ & $19,31.7 \%$ & $25,41.7 \%$ & $32,53.3 \%$ \\
\hline
\end{tabular}

According to the survey for the Miao nationality、Dong Minority、Mulao nationality and Mao Nan nationality in 2013 and 2014, we found that there are members who work out. The minimum proportion is Dong nationality(25.0\%), the highest is Maonan nationality(48.3\%) in 2013. In 2014, the lowest is still Dong nationality (31.7\%) and raises about six percentage points than 2013. The highest is Maonan nationality (53.3\%), raising five- point. Careful contrast of the proportion of working out above the four nationalities between 2013 and 2014 shows up its increase. The biggest growth range is Yao nationality, reaching to 13.4 percent. Thus it can be seen, the number of migrant workers is increasing gradually.

Table 2 The age of statistics chart which statistic the population of migrant workers the Miao nationality 、 Dong Minority、Mulao nationality and Mao Nan nationality at the area of northwest in Guangxi province

\begin{tabular}{|c|c|c|c|c|c|c|c|c|c|c|c|c|c|c|}
\hline \multirow{2}{*}{$\begin{array}{l}\text { Time } \\
2013\end{array}$} & \multicolumn{2}{|c|}{$\frac{15-18}{\text { Male Female }}$} & \multicolumn{2}{|c|}{ Male Female } & \multicolumn{2}{|c|}{ Male Female } & \multicolumn{2}{|c|}{$\frac{30-40}{\text { Male Female }}$} & \multicolumn{2}{|c|}{ Male Female } & \multicolumn{2}{|c|}{$\frac{50-60}{\text { Male Female }}$} & \multicolumn{2}{|c|}{$\underset{\text { Male Female }}{\text { Total }}$} \\
\hline & 2 & 3 & 7 & 10 & 14 & 10 & 17 & 12 & 15 & 8 & 8 & 4 & 63 & 47 \\
\hline 2014 & 3 & 6 & 9 & 14 & 18 & 18 & 20 & 14 & 20 & 8 & 9 & 6 & 79 & 66 \\
\hline
\end{tabular}

In 2013, there are 240 families including the Miao nationality、Dong Minority、Mulao nationality and Mao Nan nationality in the sampling survey. 11 people gave up traditional agricultural production, deciding to go out to work. The age of migrant workers is from 15 to 60 years old , containing the ethnic minority resident from teenage to middle and old age people. The number of working out is 145 persons in 2014, has increased 31.8 percent and rise fast. According to the analyses about the age of migrant workers, the ethnic minority residents of migrant workers are increasing at any age group in 2013 and 2014. The under-age of residents between 15 and 18 years old have increased from 5 people to 9, increasing to 80 percent even more obvious, the number of girls is more than boys. During 19 to 23, the young people are from 17 persons to 19, increasing 35.3 percent. Its number is still girls over boys. Migrant workers of young from 24 persons to 36 persons, its increase rate is 50 percent, however, the number of men start to catch up the women. As far as the volume, resident of migrant workers, male are more than female. 


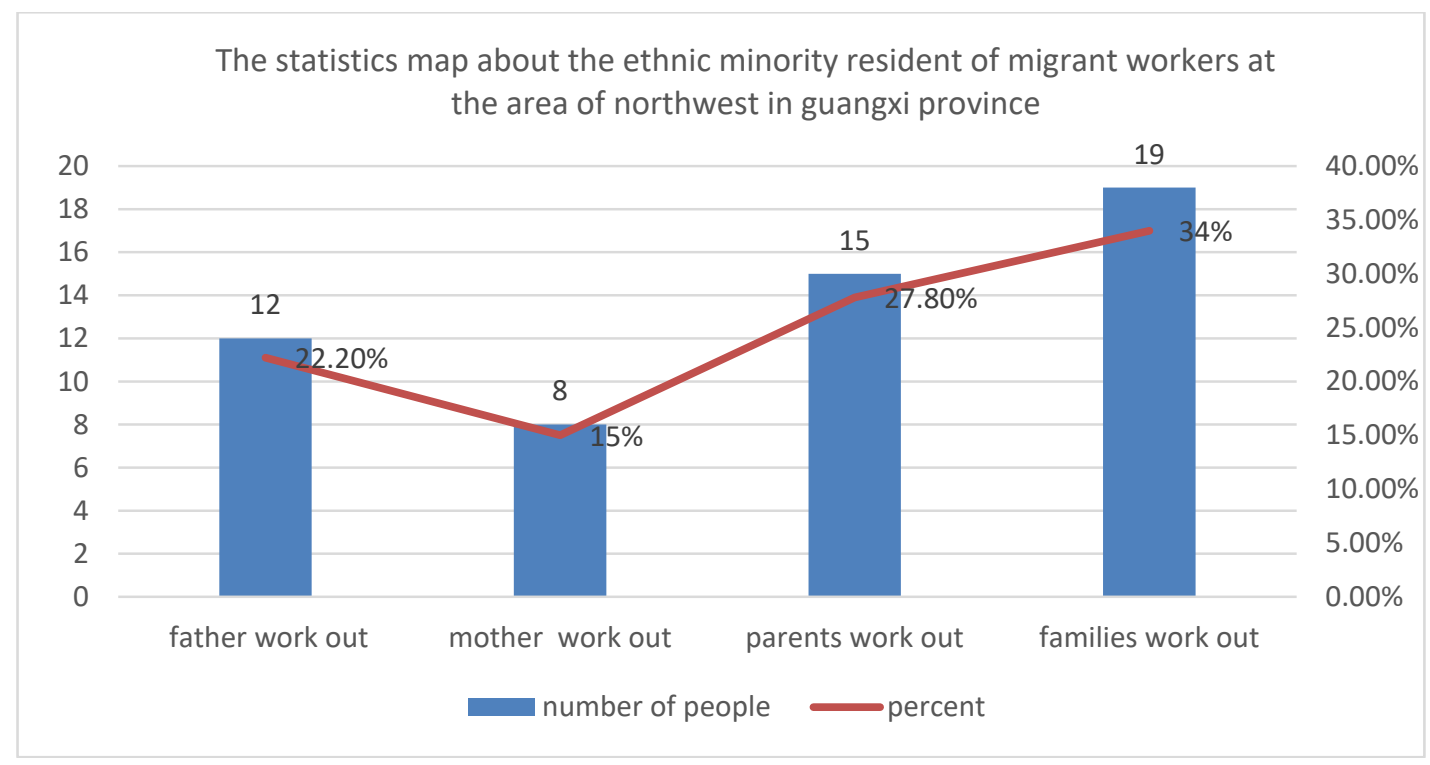

Fig 1 The statistics map about the ethnic minority resident of migrant workers at the area of northwest in Guangxi province.

The survey that is about the ethnic minority at the area of northwest in Guangxi province including the Miao nationality Dong Minority, MulaonationalityandMaonan nationality. There are 54 married families which have a kid on education and one person at least works out. It is taken up the whole families are surveyed. Among, the number of migrant workers of fathers or mothers are 12 or 8, they are 22.2 percent and 15.0 percent; Sons and daughters are taken care of by their relatives for parents work out. It has 15 families and takes up 27.8 percent. There are 19 families of working out in the whole family and 34.0 percent.

With our country economy development and economy reform deepening, a growing number of people, the Miao nationality, Dong minority, Mulaonationality and Maonan nationality in northwest Guangxi area, chooses to go out to work. In the field survey above four minorities, the Maonan nationality accounts for the largest proportion of 53.3\%, while the Dong minority is the least with $31.7 \%$. According to the data researched, the migrant family proportion is a little high. From the view of quantitative proportion of migrant families, there is a large age span, ranging from the teenager to the elderly. What's more, in married households, at least, one member of the 54 families goes out to work, and it is father who goes out, having $22.2 \%$ with 12 families, while mother accounting for $14.4 \%$ with 8 persons. The both parents going out to work account for $27.8 \%$ with 15 families, and the whole family out of hometown has $35.2 \%$ with 19 families. Located in the remote mountains or hilly land, relatively poor living environment, traffic inconvenience, those minorities, of northwest Guangxi were based on traditional faming and the population structure had stability before reform and open to outside world because of little contact with modern civilization. As our country continuously develops economy and commits to the people's livelihood project, minority villages in remote region impacted by the modern civilization, the minorities of northwest Guangxi begin to go out the remote mountains, and leave the hometown where they lived in for generations for foreign land. Much worse, the outflow of native increases constantly, which will lead to the change of village population structure in northwest Guangxi distracts and awaken the root of traditional ethnic sports, and even influence the inheritance and development of traditional ethnic sports.

\subsection{The strike to the traditional ethnic sports by the reform of the productivity on the background of urbanization}

Sport plays an important role in human culture, which gradually forms and develops as the human society develops. According to the research by historians and archaeologists, the original sports originate in productive labor. In order to survive and multiply, in primitive society, human beings took some actions, such as walk, run, leap, cast, climb, crawl and so on, as the most essential ability of productive labor in daily life, passing to next generation all the time. Through constantly 
promotion, original productive labor evolves into field events and track events of Olympic Games nowadays, like javelin, discuss throw and running. Consequently, the traditional ethnic sports' origin of northwest Guangxi minorities contains obvious traits of productive labor. Like Cross-bow shooting, the villagers hunted on mountains with crossbow and gained the prey shot as food. It mainly relied on family to inherit this ability. For example, the father brought the child to mountain for hunting, and then taught him the skill of Crossbow shooting and how to make it. However, with the improvement of productivity, the traditional labor ways in northwest Guangxi region has dramatically changed, and the crowed who participated in the traditional ethnic sports items relating with traditional productive labor are on the decrease, resulting in the crisis of traditional ethnic sports.

\subsection{A hit to the traditional ethnic sports by the reform of the entertainment ways on the background of urbanization}

Traditional ethnic sports in the area of northwest in Guangxi province show obvious traits of entertainments. The Mulao ethnicity's “MuJiShouDan”, reflects the life of local minority; the Maonan nationality's "DingGang" coveys the message that Maonannationality are robust, masculine and calm; the Dong nationality's "CongLingZhuiBu"displays the scene that when two minorities were faced with the harsh environment, they used their own wisdom to fight with beast bravely. Before a hit from modern civilization, the stocked villagers in the area of northwest Guangxi minorities, inconvenient traffic and informed, were basically involved in their native ethnic sports as leisure and entertainment, which stimulated the development of traditional sports. But with the economy development and poverty alleviation policy to the edge of ethnic minority areas made by our country, modern entertainment and leisure ways appears in the out-dated and informed northwest Guangxi minority areas.

Table 3 The statistical table of entertainment ways of the Miao nationality, the Dong minority, the Mulao ethnicity and the Maonan nationality

\begin{tabular}{|l|l|l|l|l|l|l|}
\hline Groups & $\begin{array}{l}\text { Chinese Game } \\
\text { Fowl }\end{array}$ & $\begin{array}{l}\text { Mow } \\
\text { grass ball }\end{array}$ & $\begin{array}{l}\text { Play } \\
\text { chicken }\end{array}$ & Top & $\begin{array}{l}\text { Walk on } \\
\text { sticks }\end{array}$ & Hit birds \\
\hline The agedness & $\sqrt{ }$ & $\sqrt{ }$ & $\sqrt{ }$ & $\sqrt{ }$ & $\sqrt{ }$ & $\sqrt{ }$ \\
\hline The middle-age & $\sqrt{ }$ & $\sqrt{ }$ & $\sqrt{ }$ & $\sqrt{ }$ & $\sqrt{ }$ & $\sqrt{ }$ \\
\hline The youth & $\sqrt{ }$ & 0 & 0 & $\sqrt{ }$ & 0 & $\sqrt{ }$ \\
\hline The early-youth & $\sqrt{ }$ & 0 & 0 & $\sqrt{ }$ & 0 & 0 \\
\hline
\end{tabular}

Notation:" $\sqrt{ }$ "represents often playing;"0"represents seldom playing; The early-youth means 7-17 years old; the youth means 18-40 years old; the middle-aged means 41-65 years old; the agedness means more than 65-year old.

According to the survey on different ages, we found that, for the low development of economy, out-of-date information, when the middle-aged and the old were in their childhood, their recreation were included almost all national sports or games with their own ethnic characteristics. Nowadays, because of the reform and the opening-up policy, quick development of economy and the process of the poverty alleviation policy, the life qualities of the northwest of Guangxi province have been improving greatly: TV, radios and DVD players have been common in people's daily life; And the spare time and the way to relax also have been more flexible. What's more, with the sweeping spread concept of the nationwide sporting exercise, especially the prevalence of basketball match in the Wang village, Guangxi province, basketball grounds were built in the natural villages of the ethnic minority regions, which made modern sports become very popular. Moreover, in the recent 10 years, square dancing has been moving from cities to villages and become very popular among the middle-aged and the old. With the advent of modern recreations and sports, the ethnic minorities' traditional sports were faced with a tremendous challenge.

\section{The strategy on how to survive the traditional sports of ethnic minorities in the northwest Guangxi province under the urbanization}

As a vast agricultural country with a majority of the population living in the countryside, the issues of agriculture, rural area and farmer are the fundamental attention of the reform and 
opening-up policy and modernization process. The construction of new socialist rural areas is the major historical task in modernization process. And the issues of agriculture, rural area, and farmer are of paramount importance beyond any other issues. As we can see, urbanization is necessary for the economic development of our country. What's more, urbanization is a must for industrialization, tertiary industry, and the construction of the new countryside.

Most of the ethnic minorities in the northwest Guangxi province are located in the distant mountain areas, and many of them lived in the countryside, so the process of urbanization will cause a significant influence on the traditional sports in the area. Even though, the steps we pursue advanced civilization never stop and the current of social progress never impede. In fact, the development of the traditional sports of the ethnic minorities in northwest Guangxi province is the contradiction between the out-of-date traditional civilization and the need for the modern technological civilization. The national unique sports civilization is formed in the venerable process of productive labor by the habitants of northwest Guangxi province. Now faced with the confrontation of modern civilization on traditional structure of population, productivity, and recreational ways, how to adjust the development direction of the traditional sports, and make them not disappear becomes a core problem.

3.1. Integrate the traditional sports projects of the ethnic minorities in the northwest Guangxi province, and stimulate the transition of them.

The inevitability of social progress and the constant development of world technologies contribute to the continuous development of productivity. And the development of productivity will change the traditional way of laboring of the ethnic minorities in the northwest Guangxi province, which can further affect the traditional ethnic sports related to productivity, like bowing, catapult and so on. It is inevitable that the backward mode of production will be eliminated when the society moves forward. If we don't integrate or adjust the direction of irrelevant traditional sports projects, they will definitely disappear. With the elevation of life quality of the ethnic minorities in the northwest of Guangxi province, and the increase of their spare time, the previous traditional sports projects aimed at productive labor should be changed into recreational and competitive sports projects by elevating the enjoyment and participation of the sports, such as holding bowing and catapult competition, and providing some substantial rewards to attract more people to participate in the recreational competition. Furthermore by the organized arrangement of government, and more participation of people in the recreational competition, the national traditional sports can be inherited and developed.

3.2. To speed up the economic development in ethnic minority areas of northwest Guangxi and keep the integrity of the population structure.

The stability and integrity of the population are both important for the development of traditional sports. The existence and development of traditional minority national sports can't be separated from the masses. And it has the characteristics of the family inheritance. The incomplete structure of population will directly affect the inheritance of traditional minority national sports. Nowadays, the issue of population flow is large in ethnic minority areas of northwest Guangxi. The main problem is the development level of local economy is low. And ethnic gather in remote mountainous areas. Production conditions are very hard. The increasing number of young people is dissatisfied with the present conditions and they choose to work outside. The reason is that the income of working outside is much higher than farming at home. Therefore, to maintain the stability of population structure in ethnic minority areas of Guangxi, we must increase the intensity of investment promotion and capital introduction. So as to the surplus labor force can make a transformation locally. Protect the fundament of growth and development of traditional sports. Make traditional sports a better development and inheritance.

\subsection{To establish base for sports culture of ethnic areas according to the traditional culture protection policy.}

With the disappearance of more and more excellent national culture,our country has paid more attention to the protection of minority ethnic culture. Today there have been relevant laws to protect the ethnic culture such as Constitution,Regional National Autonomy, and Protection of Cultural 
Relics. And some provisions of inheriting, protecting and developing ethnic minority traditional culture, helping the ethnic areas speed up economic and cultural development in the law on regional national autonomy of the republic of the Chinese nation. Our government has introduced a number of important regulations and documents, such as National cultural development plan outline for the 11th five-year period, Cultural reform development and plan for the national 12th five-year period, Minority business in the 11th five-year plan,Minority business 12th five-year plan and several opinions of the state council on further prosperity and development of ethnic minority cultural undertaking. Our country not only protects ethnic culture in laws, but also allocates funds for the development of traditional culture.

3.4 To explore comprehensive development of northwest Guangxi national traditional sports, making multi-channel development.

The traditional life customs form sports culture of northwest Guangxi minorities. Nowadays the traditional life customs have changed a lot. The development of traditional sports was hit by state policies, laws and regulations, as well as the human progress. Such as afforestation, banning hunting national protected animals directly affect the shooter of minority national sports' development. Traditional minority national sports should satisfy the social demand for sports under the new situation, keeping pace with the times, and giving full play to the advantages of traditional sports, developing fully through various channels. Such asestablishing traditional bases of northwest Guangxi, promoting the integration of northwest Guangxi ethnic traditional sports, promoting the activities of traditional sports entering schools, depending on the wonderful tourism resources in northwest Guangxi to develop tourism traditional sports projects, to promote traditional sports' development of northwest Guangxi depends on tourism. Strengthen the traditional ethnic sports' training in the ethnic areas. Improve traditional ethnic sports' influence through the competitions of the national minority games.

\section{Acknowledgments}

I would like to express my gratitude to all those who helped me during the writing of this thesis. My deepest gratitude goes first and foremost to Professor LichunWei, my supervisor, for her consta nt encouragement and guidance. He has walked me through all the stages of the writing of this thesi $\mathrm{s}$. Without his consistent and illuminating instruction, this thesis could not have reached its present $\mathrm{f}$ orm.

Second, I would like to express my heartfelt gratitude to Professor Jiangzhuo Lanwho led me int o the world of translation. I am also greatly indebted to the professors and teachers at the Departme nt of English: Ms. SuqiongFeng, Qichang Xu and Han Xiaoya, who have instructed and helped me a lot in the past two years.

Last my thanks would go to my beloved family for their loving considerations and great confide nce in me all through these years. I also owe my sincere gratitude to my friends and my Colleagues who gave me their help and time in listening to me and helping me work out my problems during th e difficult course of the thesis.

Project name : Hechi University's collegial key scientific research project with Type A in 2013“The presentcrisis and conservation study on the traditional minority national sports in the northwest of Guangxi under the background of urbanization"

Project number:2013ZA-H001

Approval document for the project: College Research Institution[2013]4 file

\section{References}

[1] Yang Yantao, Mo Weibin, Deng Wei. Guangxi minority "rural folk sports" culture development research[J]. Shandong sports technology 2014, 36 volume, the third phase P33-35 1009-9840

[2] Wei Guanghui, MengYuzhu, Liu Chaomeng. Guangxi minority traditional sports games' investigation and study [J]. Sports culture Tribune 2014, the second phase, P16-18 1671-1572 
[3] Zhang Peifeng. Inherit and Develop of Traditional Sports in Guangxi Minority Areas. [J]. Sports culture Tribune 2014 , the seventh phase, P44-47 1671-1572

[4] Zhu Lantao, Chen Wei. Guangxi minority traditional sports' investigation and study on cultural resources [J]. Researching of Guangxi minorities 2012, the third phase 1004-454X

[5] Liu Zhihong, Li Zhongguo. Research of minority villages protection and planning in the process of urbanization-ethnic minority villages in Guangxi as an example.

[6] Sun Liuzhong. Study on the sustainable development of national traditional sports[J].Journal of $\mathrm{Lu}$ Liang college of education, September,2010, the third phase, 27 volume(73 phases in total):139-140 